\title{
O GRAFITE, A PICHAÇÃO E A PROTEÇÃO DO PATRIMÔNIO CULTURAL: UMA ANÁLISE SOB O ENFOQUE DA LEGISLAÇÃO DO ESTADO DO AMAZONAS E DO MUNICÍPIO DE MANAUS
}

\author{
GRAPHITE, CULTURAL HERITAGE AND PATRIMONY: AN ANALYSIS UNDER \\ THE APPROACH TO THE LEGISLATION OF THE STATE OF THE AMAZON \\ AND THE MUNICIPALITY OF MANAUS
}

Valmir César Pozzetti ${ }^{1}$ Ari Badarane Nicolau Júnior ${ }^{2}$

\begin{abstract}
RESUMO
O objetivo do presente artigo científico é expor como a pichação, o grafite e a proteção do patrimônio cultural estão sendo encarados pelo legislador do Estado do Amazonas e do Município de Manaus, sem prejuízo da contextualização histórica do grafite e da pichação, das diferenças entre ambas as atividades e das normas internacionais que estão inseridas no arcabouço normativo pátrio, no que tange à proteção do patrimônio cultural. O método utilizado para a pesquisa foi o dedutivo; quanto aos meios o procedimento foi o bibliográfico e quanto aos fins, qualitativo. Concluiu-se que o ordenamento jurídico brasileiro possui as bases necessárias para a devida proteção do patrimônio cultural, inclusive quanto à correta diferenciação entre a pichação e o grafite, faltando, no entanto, regulamentação da matéria pelo Estado do Amazonas e Município de Manaus.
\end{abstract}

PALAVRAS-CHAVE: grafite; meio ambiente urbano; patrimônio cultural; pichação;

\begin{abstract}
The objective of this scientific article is to expose how graffiti, graffiti and the protection of cultural heritage are being considered by the legislature of the State of Amazonas and of the Municipality of Manaus, without prejudice to the historical contextualization of graffiti and graffiti, activities and international norms that are part of the normative framework of the country with regard to the protection of cultural heritage. The method used for the research was deductive; as for the means the procedure was the bibliographic and as for the ends, qualitative. It was concluded that the Brazilian legal system has the necessary bases for the proper protection of cultural heritage, including the correct differentiation between graffiti and graffiti, however, there is a lack of regulation of the matter by the State of Amazonas and Manaus.
\end{abstract}

KEYWORDS: graphite; urban environment; cultural heritage; graffiti;

1 Doutor em BioDireito /Direito Ambiental pela Université de Limoges/França. Professor Adjunto da Universidade Federal do Amazonas e Professor Adjunto da Universidade do Estado do Amazonas. Advogado e Contador. E-mail: v_pozzetti@hotmail.com.

${ }^{2}$ Aluno do Programa de Mestrado em Direito Ambiental, da Universidade do Estado do Amazonas. E-mail: aribadarane@albadvogados.com. 


\section{INTRODUÇÃO}

O grafite e a pichação suscitaram, ao longo dos anos, muita polêmica social. Antigamente ambas as práticas, por serem originárias de setores marginalizados da sociedade, a primeira como meio de denúncia e protesto, a segunda como de depredação do patrimônio público e particular, não eram dissociadas no ideário popular que as encarava como a mesma atividade.

Em tempo não muito distante, o legislador federal brasileiro criminalizava tanto o grafite como a pichação. Contudo, posteriormente fez a correta diferenciação de ambas as práticas mantendo somente a reprovação da atividade da pichação e do grafite, somente se este último não for autorizado pelo poder público ou pelos particulares cujos bens estão envolvidos na criação artística.

Nesse contexto, principalmente levando em conta a crescente representatividade que o grafite brasileiro vem ganhando a nível mundial, é imperioso averiguar se os legisladores do Estado do Amazonas e do Município de Manaus estão enfrentando corretamente a questão, antes, contudo localizando o leitor nos aspectos gerais atinentes a proteção do patrimônio cultural internacional e nacional.

A problemática desta pesquisa é: em qual contexto a pichação e o grafite passaram a ser mais utilizados ao redor do planeta e no Brasil? Quais as diferenças existentes entre a pichação e o grafite? Até que ponto o grafite já elaborado nas vias públicas e que acabam atraindo atenção da população da cidade e de turistas, se tornando verdadeiros pontos de parada para o registro de fotografias, dentre outras atividades, necessita ser preservado? Diante do contínuo debate do enquadramento do grafite elaborado nas vias públicas como patrimônio cultural, como a questão da proteção desses bens é enfrentada pela legislação nacional, regional (do Estado do Amazonas) e local (do Município de Manaus)?

Em vista disso, essa pesquisa tem por objetivo traçar o contexto histórico do soerguimento do grafite e da pichação ao redor do mundo e do Brasil, traçar as diferenças entre grafite e pichação, identificando de onde surgiram, assim como expor o arcabouço normativo nacional, regional (Estado do Amazonas) e local (Município de Manaus) voltado à proteção do patrimônio cultural e às atividades do grafite e da pichação para se concluir se o poder legislativo tem encarado devidamente a questão nessas regiões.

A pesquisa se justifica na medida em que vislumbra-se grande importância da questão ser devidamente enfrentada pelo poder legislativo nacional, regional e local para que futuros 
conflitos possam ser evitados e também para que a criação artística dos grafiteiros seja protegida dado o enorme trabalho que empreendem, os custos despendidos muitas vezes pelo próprio poder público, embora por vezes pelos particulares, e as mensagens transpassadas que na maior parte relacionam-se aos princípios da fraternidade e solidariedade e até que ponto o grafite e a pichação, ou se somente a última, ocasiona poluição ambiental na modalidade visual.

Optou-se por utilizar no presente trabalho o método dedutivo, o meio utilizado foi o bibliográfico e a finalidade é qualitativa.

No desenvolvimento desta pesquisa científica, dividimo-la em 06 (seis) partes, inicialmente buscou-se situar o leitor no contexto histórico do grafite e da pichação, diferenciar o grafite da pichação e, em seguida, transpassar-lhe quais normas internacionais foram abarcadas pelo ordenamento jurídico brasileiro e como os legisladores federal, do Estado do Amazonas e do Município de Manaus resguardaram o patrimônio cultural e encararam a questão do grafite e da pichação.

\section{BREVE CONTEXTUALIZAÇÃO HISTÓRICA DO GRAFITE E DA PICHAÇÃO}

Há muito tempo são visualizadas manifestações através da inserção de palavras e frases de efeito em imóveis urbanos com variadas finalidades.

Nesse sentido Endo (2009, p. 7) realça que:

Já na antiguidade é possível encontrar elementos de pichação. A erupção do vulcão Vesúvio preservou inscrita nos muros da cidade de Pompéia, que continham desde xingamentos até propaganda política e poesias.

Na Idade Média, padres pichavam os muros de conventos rivais no intuito de expor sua ideologia, criticar doutrinas contrárias às suas ou mesmo difamar governantes.

Todavia, a maior relevância do grafite e da pichação modernas remonta à década de 1960 quando em voga a contracultura que se tratou de um movimento social consistente no questionamento e enfrentamento dos valores vigentes e então aceitos pelas camadas mais abastadas da sociedade.

Segundo Biagi (2009, p. 1): “a Contracultura procurou promover novas maneiras para as relações sociais, culturais e políticas baseado na inovadora visão da juventude. Em outras palavras, os jovens procuraram criar uma nova cultura, uma Contracultura".

O primeiro grande palco das pichações e grafites foi a cidade de Paris, capital da França, em que os estudantes e trabalhadores de um modo geral valeram-se da inserção de 
gravuras e frases de efeito no meio ambiente urbano para protestar contra diferenças de gênero, condições laborais alarmantes, liberdades individuais, dentre outras coisas.

Já Pennachin (2003, p. 9) destaca que "o ano de 1968, na França, foi um marco para a atividade. Os muros de Paris foram cobertos, na ocasião, por frases políticas pintadas por estudantes, transformando e subvertendo os sistemas sígnicos anteriormente estabelecidos".

Nesse sentido, Ramos (2007, p. 1261) assim resume a erupção do movimento do grafite e da pichação na capital francesa:

A partir de maio, 1968, culturas jovens populares e/ou de oposição - isentos de qualquer obrigação artística, moral ou social, sem possuírem outro meio para se manifestarem ou muitas vezes nem mesmo o querendo -, começaram a ocupar alguns espaços da cidade. Entre inúmeras ações de protesto, panfletos e jornais, frases curtas e inteligentes como É proibido o trabalho alienado, É proibido proibir, A imaginação toma o poder, inscritas nos muros da cidade de Paris, marcaram a presença de jovens na história do protesto e projetaram para muitas outras cidades e grupos de jovens a transgressão lúdica de viver a cidade como espaço de comunicação. Túneis, viadutos, elevados, muros, monumentos - espaços especialmente criados e protegidos nos projetos urbanistas - passaram a ser alvo preferido dos grafiteiros.

Já Lazzarin (2007, p. 62) expõe não apenas o considerado marco do surgimento do grafite, mas a própria disseminação dele ao redor do mundo quando ressalta ser o grafite:

(...) uma forma de inscrição urbana ${ }^{2}$ com origens no movimento da contracultura, iniciado na década de 1960. Desde o início, o grafite está ligado à contestação política e ideológica e a movimentos de afirmação identitária. Primeiramente na Europa, surge como forma de manifestação política do movimento estudantil francês, cujas idéias paulatinamente se espalharam para a América, sofrendo influências, nas décadas de 70 e 80, dos movimentos hippie e punk. Nos Estados Unidos, o grafite é usado como uma forma de afirmação das comunidades negra e latina, confinadas em seus respectivos guetos, em Nova York, nos bairros do Bronx e do Brooklin. Na década de 90, torna-se um dos elementos que compõem a cultura Hip-Hop, juntamente com o Break, o Disc Jokey, o Master of Cerimony. O grafite constitui-se, então, como forma de divulgação de encontros, festas e eventos das comunidades referidas

Interessante observar que o movimento observado na Europa foi espalhado para o continente americano e para o mundo todo, a exemplo dos Estados Unidos em que os grandes atores urbanos eram os jovens, em sua maioria afrodescendentes e latinos, desfavorecidos, que moravam nas periferias urbanas e precisavam de alguma maneira expressar as mazelas sofridas e as críticas que carregavam em cada um dos seus corações, assim como influenciou outros movimentos como o hippie, o punk e o hip-hop cujos integrantes reuniam-se e como modo de entretenimento e protesto também grafitavam e pichavam.

Nesse sentido, Pozzetti e Prestes (2018, p.117) destacam que:

A Sociologia investiga essas hipóteses sobre a perspectiva da seletividade hierárquica dos serviços públicas, no sentido de que algumas políticas seriam adotadas para beneficiar prioritariamente e com melhor qualidade de vida as áreas mais ricas em detrimento das áreas mais pobres. (gn) 
As escritas e ilustrações nas zonas urbanas das cidades, contudo, não se limitaram aos protestos e à ânsia dos indivíduos se expressarem contra os desmandos da classe política, burguesa, desatualização dos costumes e preconceitos; igualmente foram utilizadas por grupos rivais para demarcar as áreas onde cada qual praticava as respectivas práticas ilícitas, o que até hoje é verificado ao redor do mundo e no território brasileiro, e como forma de competição para ver qual grupo conseguia pichar os lugares mais perigosos.

Nesse sentido Endo (2009, p. 7) explana que "No final de 1969 e início da década de 1970, as ruas de Los Angeles foram tomadas por pichações que demarcavam a disputa territorial pelo tráfico de drogas entre duas violentas gangues rivais: Bloods, representada pela cor vermelha, e Crips, representada pela cor azul”.

Ou seja, o soerguimento do grafite e da pichação remonta à flagrante necessidade que as pessoas das periferias urbanas, sempre as mais afetadas pelos desmandos daqueles que comandam a política e os negócios, têm de serem escutadas pela coletividade, seja para denunciar as injustiças vivenciadas, como para protestar por melhorias que precisam ser feitas no sistema já estabelecido para que elas também se sintam nele incluídas.

Forte exemplo tanto da relevância do movimento do grafite e da pichação como mais um veículo de expressão popular, talvez o mais democrático e acessível antes da pluralização do acesso à internet e da hegemonia das redes sociais, quanto da representatividade nas grandes etapas históricas da segunda metade do século $\mathrm{XX}$ foram as inúmeras frases e gravuras realizadas em forma de protesto no próprio muro de Berlim.

O Brasil não ficou à margem desse movimento, de acordo com Zuin $(2008$, p. 9):

(...) Foi assim que se deu: nos "alucinados" anos 70, uma comunidade de estudantes, pintores e jovens de todas as classes sociais, inconformados com o regime político da época, a ditadura militar, praticavam em vários pontos estratégicos da cidade a provocadora prática das pinturas parietais. Era um movimento que trazia em seu bojo uma nova forma de expressão das massas: as pinturas nos muros e paredes manifestadas no espaço urbano, agora no Brasil. Às pinturas parietais atuais chamamos de grafite ou pichação; (...)

Vê-se que, da mesma maneira que nas outras localidades do mundo (Europa em reconstrução depois da segunda guerra mundial, Estados Unidos recuperando-se das inúmeras perdas humanas e monetárias decorrentes da guerra do Vietnã e etc.), no Brasil a utilização do grafite e da pichação foi naquela época uma das formas de protesto à contínua centralização no Estado das decisões acerca do rumo que a vida dos indivíduos, para denunciar os abusos cometidos pelas classes dominantes e tecer críticas de um modo geral ao regime militar. 
Percebe-se, então, que a pichação e o grafite fazem parte do cenário urbano há muito tempo e são utilizados eminentemente como maneira de expressar súplicas dos indivíduos residentes em áreas urbanas de forte fragilidade social.

\section{DIFERENÇAS ENTRE GRAFITE E PICHAÇÃO}

Com o grande êxodo rural, dentre outros fatores, decorrente da inserção de novas tecnologias no campo, as cidades acabaram atraindo grande parcela da população campestre que buscava melhores condições de vida que, em alguns casos, resolveu migrar para à zona urbana em busca daquele sonho retratado nas campanhas publicitárias das grandes marcas e nos cartazes da indústria cuja avidez por mão-de-obra crescia bastante o que pressionou o fornecimento de serviços públicos essenciais e a própria disponibilidade de empregos à medida que melhoramentos tecnológicos foram sendo introduzidos nas cadeias produtivas.

Segundo Brito, Horda e Amaral, 2001, p. 2:

Os resultados do Censo Demográfico de 1940 revelaram que apenas 31,2\% da população brasileira na época, que era de 41.236 .315 habitantes, residia em áreas urbanas. Nas décadas seguintes esse percentual aumenta sistematicamente, observando-se tendência crescente de urbanização, mas é somente em 1970 que registrou-se, para o país como um todo, uma população urbana superior à rural $(55,9 \%)$. O crescimento urbano, até os dias de hoje determinaram, segundo o último levantamento censitário, um grau de urbanização de $81,2 \%$, no ano 2000. (gn)

Desse modo, no contexto brasileiro, que possui uma máquina pública extremamente ineficiente e um inóspito ambiente de negócios, em decorrência de sucessivas administrações ineficientes empreendidas por indivíduos que buscaram mais os próprios interesses que os da coletividade, o Estado teve e tem grande dificuldade de equalizar as diferenças sociais e assegurar aos cidadãos as garantias sociais básicas previstas na Constituição Federal de 1988 (art. $5^{\circ}$ e $6^{\circ}$ ), importando na marginalização de muitas famílias que acabam se vendo em situação de desespero por não terem mais a quem recorrer.

Há que se destacar que essa novel população urbana passa a desempenhar diferentes funções no âmbito urbano, dentre as quais a pichação e o grafite, como forma de manifestação de seus anseios e necessidade internos.

Mesmo que a população ainda não atente como devido para as diferenças existentes entre o grafite e a pichação, que não se confundem, Lopes $(2011$, p. 9) destaca que:

\footnotetext{
Atualmente a pichação encontra-se envolvida com grupos de gangues que fazem uso de violência para obter controle de áreas menos protegidas pelos órgãos públicos. Já, o grafite, faz parte de grupos que possuem uma visão da sociedade e procuram, por meio da arte, tentar fornecer meios de reflexão. Eles são executados em muros com consentimento prévio, pois além de ser uma forma de manifestação, são mais elaborados e demandam mais tempo. (gn)
} 
Os jovens originados daquelas famílias que vivem em condições menos favorecidas e em zonas marginais dos grandes centros urbanos, alguns com espírito crítico, resultado da maior lucidez em relação às causas das dificuldades que enfrentavam e da escassez cada vez maior de oportunidades à disposição deles, em comparação com aqueles de lares mais abastados, começaram a valer-se do cenário urbano para denunciar todos os abusos sofridos por pessoas nas mesmas condições que eles e, igualmente, expor através de ilustrações em bens públicos e particulares, as respectivas impressões do meio ambiente urbano e o social em que estão inseridos.

Vê-se, portanto, que pichação e grafite surgiram em virtude de confrontos de direitos entre os migrantes (e seus descendentes) do campo, que chegam aos centros urbanos em completa desigualdade e invisibilidade em relação à classe urbana abastada e, através da pichação e grafitagem procuram se fazer visíveis, aceitos e integrados à sociedade, querendo ocupar espaços.

De outra forma, é bem verdade que muitos dos jovens que vivem em situação de fragilidade social, por fatores diversos, continuam presos sob os véus da ignorância que lhes retira a nitidez dos olhos fazendo-os percorrer caminhos contrários à lei, ética, moral e aos bons costumes. Esse grupo termina por se envolver em gangues que rivalizam com outras pelo domínio dos territórios onde praticam seus crimes ou simplesmente na busca de objetivos que justificam a prática da violência e depredação do patrimônio público e particular.

Dessa forma, verifica-se que o primeiro grupo, que pratica o grafite manifesta-se de maneira eminentemente crítica visando que a sociedade os escute, lhes dê valor, acorde e enxergue que pessoas reais são prejudicadas com os desmandos originários de um sistema político falido e de uma economia de mercado que sofre graças as contínuas e desmedidas intervenções do Estado que, por vezes, exorbita o poder que lhe foi conferido pelo legislador constituinte criando discrepâncias e competidores inatingíveis, assim as ilustrações e frases de efeito elaboradas por eles representam súplicas às pessoas para que acordem e lutem pelas mudanças sociais que se fazem necessárias.

Ou seja, o grafite é a maneira encontrada por uma parcela dos indivíduos da sociedade de retratarem como encaram a "selva" urbana, assim como se tornou ferramenta de crítica popular e inclusão social cujos trabalhos de determinados artistas brasileiros, inclusive, gozam de ampla aceitação e admiração no mundo inteiro. 
Por outro lado, os jovens situados no outro limite, pichação, que cederam ao crime e à balburdia somente depredam o patrimônio público e particular sem o desiderato de passar alguma mensagem além da tentativa de gerar caos, desordem, demarcar áreas de exercício de atividades ilícitas, a vitória de competições entre os grupos sobre quais conseguem pichar suas assinaturas ou desenhos, sem conotação artística ou preocupação estética nos lugares mais perigosos. Estes são os expoentes da pichação.

Lazzarin (2007, p 63) afirma que:

O senso comum costuma confundir pichação com grafite. A primeira, entretanto, parece permanecer em um nível de confrontação violenta e provocação da autoridade, sem qualquer pretensão artística. Insere-se em uma espécie de jogo, com dois desafios a serem vencidos, um interno e outro externo ao grupo dos pichadores: deixar sua marca no lugar de mais difícil acesso - seja pela topografia, seja pela vigilância ou proibição de acesso - e não ser pego pela polícia ou vigilância. Quem vence esses desafios é respeitado e legitimado como participante do grupo. Enquanto o pichador quer ser conhecido apenas dentro de seu grupo, o grafiteiro almeja visibilidade e reconhecimento como artista pela sociedade. Um ponto comum que permanece entre pichação e grafite é a assinatura pessoal, chamada de tag. Essa é a marca registrada, o sinal de autoria da obra, e todo grafiteiro ou pichador tem o seu. (gn)

Quanto à licitude ou ilicitude da pichação e do grafite, a Lei n. 9.605/98, chamada de Lei de Crimes Ambientais Federais, criminalizava no seu artigo 65 ambas as condutas dado o ideário popular de que as duas diziam respeito à externalização da rebeldia popular que culminava em danos ao patrimônio público, particular, à moral coletiva e ao meio ambiente por causa da poluição visual causada.

Depois de provocado em relação ao tema, encampando também a maior conscientização das pessoas de que o grafite e a pichação são atividades distintas, o legislador federal terminou por encarar devidamente a questão e descriminalizou o grafite com a edição, e posterior entrada em vigor, da Lei n. $12.408 / 2011$ com a nova redação que o seu artigo $6^{\circ}$ deu ao art. 65 da Lei de Crimes Ambientais Federais.

Art. 6o $\mathrm{O}$ art. 65 da Lei no 9.605 , de 12 de fevereiro de 1998, passa a vigorar com a seguinte redação:

Art. 65. Pichar ou por outro meio conspurcar edificação ou monumento urbano:

Pena - detenção, de 3 (três) meses a 1 (um) ano, e multa.

$\S 1$ o Se o ato for realizado em monumento ou coisa tombada em virtude do seu valor artístico, arqueológico ou histórico, a pena é de 6 (seis) meses a 1 (um) ano de detenção e multa.

§ 2 Não constitui crime a prática de grafite realizada com o objetivo de valorizar o patrimônio público ou privado mediante manifestação artística, desde que consentida pelo proprietário e, quando couber, pelo locatário ou arrendatário do bem privado e, no caso de bem público, com a autorização do órgão competente e a observância das posturas municipais e das normas editadas pelos 
órgãos governamentais responsáveis pela preservação e conservação do patrimônio histórico e artístico nacional. (gn)

Certamente a criminalização da pichação visa além do resguardo do patrimônio público e particular igualmente coibir a propagação da poluição visual nos grandes centros urbanos que é tema objeto de numerosos estudos dadas as consequências anímicas geradas nos indivíduos a depender da gravidade.

Nesse sentido Ramos (2012, p. 1) discorre que:

Nesse diapasão, o que choca na pichação não é somente o desrespeito ao patrimônio alheio ou a poluição visual causada que, longe de expressarem liberdade de expressão, as pichações atuais mais se assemelham a atos de vandalismo gratuito contra o ordenamento urbano das cidades. (gn)

Já para Silva (2003, p. 171) Poluição Visual é definida como sendo:

(...) a degradação da qualidade ambiental resultante de atividades que direta ou indiretamente afetam as condições estéticas do meio ambiente. A redação da letra "d" do inciso III do artigo $3^{\circ}$ da Lei $n^{\circ}$ 6.938/81 é inequívoca! Entretanto, os limites do que seja "afetar as condições estéticas do meio ambiente" não foram fixados nem pelo legislador pátrio nem pelos magistrados - com exceção ao que diz respeito às paisagens notórias. A indagação que se coloca é: toda e qualquer modificação das condições estéticas do meio ambiente resultam em uma poluição visual? Certamente a resposta a essa pergunta é negativa, pois apenas as modificações estéticas que degradem a qualidade ambiental podem ser conceituadas como poluição visual. Ainda pode ser considerada poluição visual aquela que prejudique a saúde e o bemestar da população (art. 30 , III, "a", da Lei $n^{\circ} 6.938 / 81$ ), ou que crie condições adversas às atividades sociais e econômicas (art. $3^{\circ}$, III, "b", da Lei n' 6.938/81). (gn)

Mas, veja-se que o grafite, da mesma forma que a pichação, pode ser enquadrado no núcleo do tipo, desde que feito sem autorização do poder público ou dos particulares cujos bens sejam afetados pela atividade como esclarece Gontijo (2012, p. 46):

A descriminalização, como já se mencionou anteriormente, deu-se apenas em relação ao grafite feito com autorização e, no núcleo do tipo, destacou-se que, para ele deixar de ser crime, é necessário, também, tratar-se de manifestação artística realizada com o objetivo de valorizar o patrimônio público ou particular. (gn)

Essa realmente é a melhor interpretação: devem ser resguardados os grafites feitos com autorização do poder público e dos particulares, caso contrário, se feitos à revelia, em virtude da necessidade de resguardar a ordem pública e o hígido convívio entre os habitantes da sociedade, em prol da manutenção do Estado de Direito, a solução é infelizmente erradicálos do cenário urbano, depois do devido registro virtual, mesmo que se tratem de manifestações individuais que demonstrem características das jornadas diárias de muitas coletividades, assim como das críticas que somente ganham vida a partir das ilustrações urbanas.

Portanto, hodiernamente faz-se a correta diferenciação entre a pichação, que constitui ilícito penal, dadas às características e motivação eminentemente danosa da prática tanto ao 
patrimônio dos indivíduos como ao meio ambiente urbano, e o grafite que se tornou via de expressão artística de valorada aceitação e admiração social.

\section{PATRIMÔNIO CULTURAL UNIVERSAL}

O mundo contemporâneo, mesmo ainda não tendo superado a divisão da sociedade global em organismos jurídicos distintos (Estados), deve reconhecer cada vez mais o indivíduo como ocupante de uma sociedade mundial diversificada e dotada de patrimônio cultural próprio, cuja soberania deve ser resguardada.

Dessa forma, todo grupo social, independentemente da sociedade e da nação da qual façam parte, merece a proteção universal da manutenção dos traços culturais que lhes são característicos e a garantia da externalização da própria cultura cabendo às nações desenvolverem normas supranacionais que não somente garantam a perfectibilização da expressão cultural, mas a salvaguarda dessas manifestações, para a posteridade.

A cultura e a defesa do patrimônio cultural inserem-se na família dos direitos constitucionais de $2^{\mathrm{a}}$ (segunda) geração que demandam uma postura ativa dos cidadãos e dos Estados para que sejam garantidos.

Nesse sentido Bulos (2011, p.518):

A segunda geração, advinda logo após a Primeira Grande Guerra, compreende os
direitos sociais, econômicos e culturais, os quais visam assegurar o bem-estar e a
igualdade, impondo ao Estado uma prestação positiva, no sentido de fazer algo de
natureza social em favor do homem. (gn)

Ou seja, a cultura e o patrimônio cultural merecem a proteção dos indivíduos e instituições existentes na sociedade atual para que futuramente os membros que compuserem a sociedade possam, de igual maneira que os seus antepassados o fizeram, aprender acerca da evolução das manifestações de cada grupo social pela observação contemporânea das externalizações efetuadas em qualquer dos cenários, seja ele urbano ou não urbano, o que está também intimamente ligado ao princípio da solidariedade e fraternidade.

A nível internacional a preocupação com a preservação do patrimônio cultural resultou, na década de 70 do século XX, na edição, pela United Nations Educational, Scientific and Cultural Organization (UNESCO), da Convenção para a Proteção do Patrimônio Mundial, Cultural e Natural, que foi ratificada pelo Brasil.

Essa convenção, conceituou, sob o ponto de vista da proposta de preservação do patrimônio cultural de relevância universal, o que seria patrimônio cultural:

ARTIGO 1. Para os fins da presente Convenção, são considerados "patrimônio cultural": 
- os monumentos: obras arquitetônicas, esculturas ou pinturas monumentais, objetos ou estruturas arqueológicas, inscrições, grutas e conjuntos de valor universal excepcional do ponto de vista da história, da arte ou da ciência,

- os conjuntos: grupos de construções isoladas ou reunidas, que, por sua arquitetura, unidade ou integração à paisagem, têm valor universal excepcional do ponto de vista da história, da arte ou da ciência,

- os sítios: obras do homem ou obras conjugadas do homem e da natureza, bem como áreas, que incluem os sítios arqueológicos, de valor universal excepcional do ponto de vista histórico, estético, etnológico ou antropológico.

Nesse mesmo sentido é importante dizer que essa Convenção ainda destaca:

ARTIGO 4. Cada Estado-parte da presente Convenção reconhece que lhe compete identificar, proteger, conservar, valorizar e transmitir às gerações futuras o patrimônio cultural e natural situado em seu território. $O$ Estado-parte envidará esforços nesse sentido, tanto com recursos próprios como, se necessário, mediante assistência e cooperação internacionais às quais poderá recorrer, especialmente nos planos financeiro, artístico, científico e técnico. (gn)

Já no século XXI, em 2003, foi aprovada a Convenção para Salvaguarda do Patrimônio Cultural Imaterial da UNESCO que veio suplantar uma lacuna existente haja vista que a Convenção de 1.973 se voltou ao patrimônio cultural material., que assim estabelece:

Artigo $2^{\circ}$ Patrimônio cultural imaterial diz respeito às:

(...) práticas, representações, expressões, conhecimentos e competências - bem como os instrumentos, objectos, artefactos e espaços culturais que lhes estão associados - que as comunidades, grupos e, eventualmente, indivíduos reconhecem como fazendo parte do seu património cultural. Este património cultural imaterial, transmitido de geração em geração, é constantemente recriado pelas comunidades e grupos em função do seu meio envolvente, da sua interação com a natureza e da sua história, e confere-lhes um sentido de identidade e de continuidade, contribuindo assim para promover o respeito da diversidade cultural e a criatividade humana. Para efeitos da presente Convenção, só será tomado em consideração o património cultural imaterial que seja compatível com os instrumentos internacionais relativos aos direitos humanos existentes, bem como com a exigência do respeito mútuo entre comunidades, grupos e indivíduos, e de um desenvolvimento sustentável. (gn)

Assim a necessidade de preservação do patrimônio cultural material e imaterial externalizados pelos grupos sociais que compõem os Estados é tema de considerável importância que chamou atenção da comunidade internacional fortemente influenciada pelas perdas irreparáveis, observadas nas grandes guerras mundiais, desde o século passado e, por isso, foi normatizado, já tendo o Brasil aderido às duas Convenções Internacionais (1.973 e 2003).

\section{PROTEÇÃO LEGAL DO PATRIMÔNIO CULTURAL NO BRASIL}

O legislador brasileiro ao promulgar uma das constituições mais modernas do mundo e sensível em relação aos problemas sociais enfrentados pelo povo, também destacou uma 
grande importância à cultura, prevendo-a em seu texto legal, conforme esclarece Silva (2018, p. 315):

\begin{abstract}
A constituição de 1988 deu relevante importância à cultura, tomado esse termo em sentido abrangente da formação educacional do povo, expressão criadora da pessoa e das projeções do espírito humano materializadas em suportes expressivos, portadores de referências à identidade, à ação, à memória dos diferentes grupos formadores da sociedade brasileira, que se exprimem por vários de seus artigos (art. $5^{\circ}$, IX, 23, III a V, 24, VII a IX, 30, IX, e 205 a 217), formando aquilo que se denomina ordem constitucional da cultura, ou constituição cultural ${ }^{9}$, constituída pelo conjunto de normas que contêm referências culturais e disposições consubstanciadoras dos direitos sociais relativos à educação e cultura.
\end{abstract}

Assim, a CF/88 encara de maneira louvável a cultura e a proteção do patrimônio cultural assegurando, igualmente, no artigo $5^{\circ}$, IX, que "é livre a expressão da atividade intelectual, artística, científica e de comunicação, independentemente de censura ou licença”.

Todavia, o que é cultura? O significado da palavra é polissêmico, isto é, não se esvai unitariamente. De acordo com Bulos (2011, p. 1568), cultura, na acepção do legislador constituinte de 1988 tem dois significados, no viés comum significa: “(...) todo fazer humano, incluindo-se aí uma qualificação ou aptidão espiritual. Daí manifestações artísticas, poéticas, intelectuais, científicas, musicais e etc.”.

Na mesma linha de raciocínio, Bulos (2011, p. 1568) define cultura no viés técnico como:

O conjunto de hábitos do homem na vida em sociedade, condicionando seu comportamento, suas reações, seu modo de ser. Nesse aspecto, entram os costumes e o modus vivendi do ser humano. Nessa acepção, exsurge a terminologia, constituição cultural, para exteriorizar a ideia de aptidão, origem do povo, seu potencial de expressão, sua memória histórica, filosófica e sociológica.

Consignou-se que a competência para a promoção da garantia ao acesso à cultura e proteção do patrimônio cultural é comum dos entes federativos (União, estados-membros, Municípios e Distrito Federal), assim como que a União, os estados-membros e o Distrito Federal têm competência legislativa concorrente para legislar acerca da matéria (artigos 23, III a V e 24, VII a IX da CF/88).

De igual modo, a CF/88 fixa, no artigo 30, IX, o dever dos Municípios assegurarem, no âmbito local, a proteção do patrimônio histórico-cultural observando e respeitando, contudo, as ações fiscalizadoras federais, a legislação federal e estadual.

A questão foi tão bem enfrentada pela CF/88 que, no artigo 215, caput, há previsão de que o Estado "garantirá a todos o pleno exercício dos direitos culturais e acesso às fontes da cultura nacional, e apoiará e incentivará a valorização e a difusão das manifestações culturais". 
Nessa linha, o legislador constituinte, no artigo 216 da CRFB/88, definiu que o patrimônio cultural brasileiro é constituído pelos "bens de natureza material e imaterial, tomados individualmente ou em conjunto, portadores de referência à identidade, à ação, à memória dos diferentes grupos formadores da sociedade brasileira (...)”.

E também trouxe os mecanismos pelos quais o Estado poderá protegê-lo conforme Sirvinkas (2012, p. 183) esclarece:

Incumbe ao Poder Público proteger o patrimônio cultural brasileiro por meio de inventários, registros, vigilância, tombamento e desapropriação (art. 216, § $1^{\circ}$, da CF). Tombar é o ato de registrar o tombamento no Livro n. 3 do Registro de Imóveis, bem como no Livro do Tombo Arqueológico, Etnológico e Paisagístico, Livro do Tombo Histórico, Livro do Tombo das Belas Artes, Livro do Tombo das Artes Aplicadas (art. $4^{\circ}$ do Dec.-Lei n. 25/37) e no Livro do Tombo das Artes Populares no Estado de São Paulo).

Dando concreção ao mandamento constitucional que estabelece que cabe aos municípios o dever de garantir a proteção do patrimônio histórico e cultural, o município de Manaus atendendo ao espírito constitucional fixou na sua Lei Orgânica os desideratos de assegurá-lo, conforme será esmiuçado no item 7 desta pesquisa.

\section{GRAFITE COMO PATRIMÔNIO CULTURAL E O MEIO AMBIENTE VISUAL}

O meio ambiente ecologicamente equilibrado é resguardado pelo art. 225 da CF/88 cujo caput reza que: "todos têm direito ao meio ambiente ecologicamente equilibrado, bem de uso comum do povo e essencial à sadia qualidade de vida, impondo-se ao Poder Público e à coletividade o dever de defendê-lo e preservá-lo para as presentes e futuras gerações".

Sendo que o conceito de meio ambiente ecologicamente equilibrado pode ser retirado do art. $3^{\circ}$, I, da Lei n. 6.938/81 - PNMA - Política nacional do Meio Ambiente:

Art $3^{\circ}$ - Para os fins previstos nesta Lei, entende-se por:

I - meio ambiente, o conjunto de condições, leis, influências e interações de ordem física, química e biológica, que permite, abriga e rege a vida em todas as suas formas;

Ou seja, o conceito retratado pela PNMA não restringe-se ao meio ambiente natural, e Silva (1998, p. 2) o elastece definindo-o como: “a interação do conjunto de elementos naturais, artificiais e culturais que propiciem o desenvolvimento equilibrado da vida em todas as suas formas".

Já Sirvinkas (2012, p. 127) faz o seguinte comentário: 
Partindo desse conceito doutrinário, podemos dividir o meio ambiente em: a) meio ambiente natural - integra a atmosfera, as águas interiores, superficiais e subterrânea, os estatuários, o mar territorial, o solo, o subsolo, os elementos da biosfera, a fauna, a flora, a biodiversidade, o patrimônio genético e a zona costeira (art. 225 da $\mathrm{CF}$ ); b) meio ambiente cultural - integra os bens de natureza material e imaterial, os conjuntos urbanos e sítios de valor histórico, paisagístico, artístico, arqueológico, paleontológico, ecológico e científico (arts. 215 e 216 da CF); c) meio ambiente artificial - integra os equipamentos urbanos, os edifícios comunitários (arquivo, registro, biblioteca, pinacoteca, museu, instalação científica ou similar) (arts. 21, XX, 182 e s. e 225 da CF); d) meio ambiente do trabalho $^{32}$ - integra a proteção do homem em seu local de trabalho, com observância às normas de segurança (arts. $7^{\circ}$, XXII, e 200, VII e VIII, ambos da CF).(gn)

O grafite, assim, está intimamente relacionado ao meio ambiente cultural sendo abarcado pelo patrimônio cultural nacional.

Pode-se afirmnar que a parcela da população que não nutre prazer em observar as ilustrações tenha o direito de não as observar no ambiente urbano, porém de outro lado existe a necessidade de resguardar inúmeros princípios constitucionais e outros que transcendem os próprios Estados.

Tais princípios ligam-se à proteção de bens tão caros à vida humana que relativizá-los importaria num esforço contrário à luta pela perpetuação da espécie no cosmos, como por exemplo: a fraternidade, liberdade de expressão cultural, solidariedade, igualdade, dignidade da pessoa humana.

Nesse sentido Pozzetti e Prestes (2018, p.119) esclarecem que:

Merecem atenção especial da esfera pública, a igual abrangência, regularidade e distribuição dos serviços de coleta de lixo, coleta de esgoto e abastecimento de água, pois o comando Constitucional da Dignidade da Pessoa Humana tem como raiz o bem-estar de todos sem distinção de classes, sendo o Poder Público um importante vetor estratégico para implantação destas políticas públicas socioambientais.

Encampado no lema da Revolução Francesa ao lado da igualdade e da liberdade, o princípio da fraternidade está intrinsecamente ligado ao princípio da dignidade da pessoa humana na medida em que chama atenção justamente para o aspecto de que os homens vivem em comunidade e devem respeitar-se mutuamente como tal encarando que todos possuem iguais direitos e obrigações posto que suas existências estão intrinsecamente ligadas e, graças a isso, imperiosos o respeito e consideração mútuos.

Complementando, Resta; Jaborandy e Martini (1982, p. 100) afirmam que a fraternidade se encaminha:

(...) portanto, para a realização de um processo mediador construtivo da interação comunicativa, agindo no enfrentamento dos conflitos sociais e culturais. De modo 
geral, a autenticidade da razão fraterna vem a partir da consciência individual e coletiva como condição essencial para a aplicação da dignidade humana. De fato, a dignidade exige a autenticidade do sujeito que conhece e reconhece a relação com o outro e, nessa condição, apreende o sistema das tradições jurídicas e políticas que permeiam as estruturas sociais. (gn)

Dada a importância do princípio da Fraternidade, a Declaração Universal dos Direitos Humanos consignou-o logo no artigo primeiro ao estipular que: "todos os seres humanos nascem livres e iguais em dignidade e direitos. São dotados de razão e consciência e devem agir em relação uns aos outros com espírito de fraternidade".

Ou seja, se determinadas classes sociais não nutrem apego ou admiração pelos grafites ou os consideram pouco atrativos do ponto de vista estético, há de se considerar que existem aquelas que se inspiram com a observação dos desenhos que retratam em boa medida a realidade social, política e econômica dos locais em que a formação humana dos artistas foi inicialmente tecida e que, às vezes, é coincidente com a delas, gerando-lhes o sentimento de representação.

Ainda que muito se discuta até que ponto o grafite gera poluição ambiental, na modalidade visual, assim como a necessidade de resguardá-los e preservá-los contra a possibilidade do poder público erradicá-los a qualquer momento do cenário urbano, é de se destacar que o grafite hodiernamente é tido como expressão artística componente da cultura das cidades.

Nesse sentido, Gontijo (2012, p. 46) discorre que:

O que se tem hoje em relação ao graffiti é que ele foi incorporado à cultura, isto é, passou a ser aceito pela sociedade e pelo mercado de arte. Mas ele ainda é, também, arte de rua, marginal, convivendo com esse outro lado de crescente valorização de suas práticas e técnicas como arte e cultura, tanto pelo mercado da arte, quanto pelo Estado no que se refere a sua presença como arte ensinada no sistema socioeducativo e educacional puro e simples. (gn)

Não apenas isso é verdade, como tem crescido o fornecimento de patrocínio do poder público para que artistas renomados grafitem determinados bens públicos para aformosear os espaços e garantir que a população e os turistas, gratuitamente, possam deleitar-se com os trabalhos belíssimos, extremamente criativos, que transpassam muitas vezes mensagens construtivas com viés de mudança de paradigmas sociais.

Além do incentivo público, muitos particulares têm patrocinado pinturas de murais nas zonas urbanas ou custeado a elaboração desses trabalhos nas suas propriedades.

Então, tratam-se os grafites muito mais do que a expressão criativa dos artistas (grafiteiros) haja vista que eles terminam por conceder voz a uma imensa massa de indivíduos 
sem rosto, sem voz, que há muito, consoante Pozzetti (2019, a) "perderam a soberania de se portarem diante dos abusos que suportam no dia a dia com altivez e visão crítica"1.

Por isso, impedir totalmente a realização dos grafites significa silenciar essa parcela da população que vive em condições de grande fragilidade econômico-social.

Não se pode olvidar que deve haver uma maior preocupação na preservação dos grafites. Uma boa ideia é, a exemplo do que os grandes museus e a empresa google, através do produto Google Arts Project que digitalizaram os acervos de obras de artes e disponibilizaram-nos na internet, empreender a virtualização profissional dos desenhos e a disponibilização deles em museus online ou mesmo a impressão e reprodução em tamanho natural em exposições com ingressos vendidos ao público em geral como forma de arrecadar dinheiro para incentivar o desenvolvimento de novos trabalhos culturais ou mesmo amortizar a dura realidade vivenciada nas zonas marginais das cidades de onde saem, em sua maioria, as criativas mentes que praticam o grafite.

Isso permite a contínua, mas não constante, alteração das pinturas e obras vistas no cenário urbano que acabarão retratando, ao longo do tempo, as transformações vivenciadas pela sociedade ou a manutenção das mesmas mazelas outrora existentes.

Tudo isso de forma a garantir que aquelas expressões que constituem o patrimônio público nacional e retratam, dentre outros assuntos, críticas sociais, políticas e grande parte das mazelas enfrentadas por grande número de cidadãos menos favorecidos não sejam suprimidas, bem como se garanta a posteridade da criatividade de um grande número de cidadãos, para que no futuro se observem as mudanças e desafios que a sociedade teve de enfrentar ao longo do tempo, em prol do próprio aperfeiçoamento, a partir da análise da diferença entre as obras do hoje e do amanhã.

\section{GRAFITE, PICHAÇÃO E O PATRIMÔNIO CULTURAL NO ÂMBITO DO ESTADO DO AMAZONAS E NO MUNICÍPIO DE MANAUS}

O Estado do Amazonas, dando concreção aos mandamentos constitucionais que atribuem a competência conjunta dos entes federativos para manutenção do patrimônio histórico, artístico, cultural e paisagístico, assim como proporcionar o acesso à cultura e proteção do meio ambiente, previu no art. 17, incisos III, IV, V e VI, da Constituição Estadual - CE/AM, respectivamente, que compete-lhe "proteger os documentos, as obras e

\footnotetext{
${ }^{1}$ Informação verbal obtida durante às aulas de 20 mai. 2019, na disciplina Direito Urbanístico, ministrada pelo Professor Dr. Valmir César Pozzetti, do curso de Mestrado em Direito Ambiental da Universidade do Estado do Amazonas.
} 
outros bens de valor histórico, artístico e cultural, os monumentos, as paisagens naturais notáveis e os sítios arqueológicos", "impedir a evasão, a destruição e a descaracterização de obras de arte e de outros bens de valor histórico, artístico e cultural", "proporcionar os meios de acesso à cultura, à educação, à ciência e à tecnologia" e "proteger o meio ambiente e combater a poluição em qualquer de suas formas".

Já no art. 18, incisos VI, VII, VIII e IX da CE/AM, que é uma repetição do art. 24 da $\mathrm{CF} / 88$, estão previstas as competências legislativas concorrentes às da União no que tange à proteção do meio ambiente, cultura e patrimônio cultural, que consistem na elaboração de normas sobre "florestas, caça, pesca, fauna, conservação da natureza, defesa do solo e dos recursos naturais, proteção do meio ambiente e controle da poluição", "proteção ao patrimônio histórico, cultural, artístico, turístico e paisagístico, "responsabilidade por dano ao meio ambiente, ao consumidor, a bens e direitos de valor artístico, estético, histórico, turístico e paisagístico" e "educação, cultura, ensino e desporto".

Elencou-se no art. 92 da CE/AM que o Ministério Público do Estado do Amazonas, como "curador da proteção e defesa do meio ambiente e do patrimônio cultural e do consumidor".

Ademais, a Constituição do Amazonas estipula no art. 205 que o poder público estadual e municipal vão atuar em conjunto para garantir a todos o pleno exercício dos direitos culturais "e o acesso às fontes da cultura nacional e estadual, e apoiará e incentivará a valorização e a difusão das manifestações culturais (...)" e, nos incisos V, VI, VII, VIII, IX e $\mathrm{X}$ uma série de medidas visando não apenas a promoção da cultura através da valorização dos artistas, como prevendo a criação de estímulos que possibilitem o investimento de empresas na produção cultural no âmbito do Estado e também mecanismos jurídicos para proteção dos bens culturais.

Também foi regulada a criação do Fundo Estadual de Cultura na CE/AM:

Art. 205. O Poder Público Estadual e Municipal garantirá a todos o pleno exercício dos direitos culturais e o acesso às fontes da cultura nacional e estadual, e apoiará e incentivará a valorização e a difusão das manifestações culturais, através de:

\section{(...) omissis}

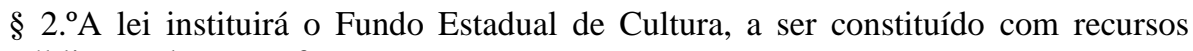
públicos e de outras fontes.

O parágrafo segundo daquela norma e no terceiro estipulou-se que o Estado do Amazonas aplicará metade das receitas do fundo em programas administrados por ele e a 
outra metade será destinada a instituições culturais constituídas e rotuladas como de "utilidade pública”.

Já no art. 206 a CE/AM relacionou quais os bens componentes do patrimônio cultural do estado:

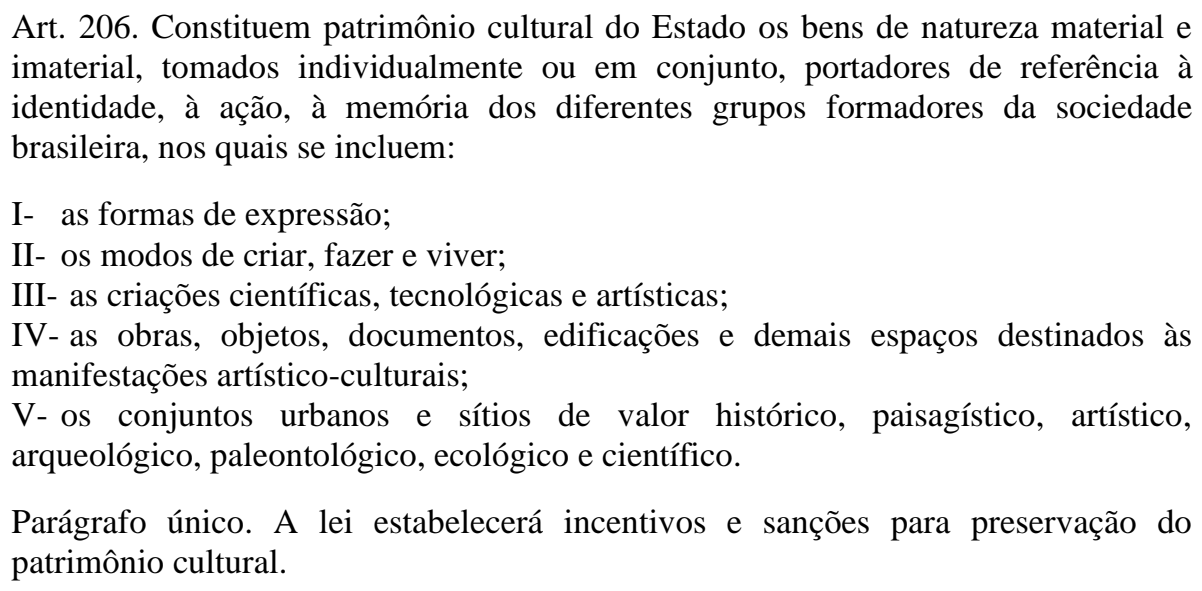

E no art. 207, conclamou que a proteção desse patrimônio será exercida pelo estadomembro em conjunto com a comunidade "por meio de inventário, registros, vigilância, tombamento, desapropriação e outras formas de acautelamento e preservação e, ainda, de repressão aos danos e ameaças a esse patrimônio".

Por outro lado, a Lei Orgânica do Município de Manaus (LOMAN) prevê que compete ao Município a proteção do patrimônio cultural e artístico, assim como incentivar a cultura e promover o lazer (art. $8^{\circ}$, incisos IX e X).

A LOMAN também dispõe que a soberania popular será exercida, dentre outros modos, como mecanismo permanente de controle da legalidade e moralidade dos atos praticados pelos poderes municipais, através de representantes escolhidos de maneira democrática que comporão órgãos de natureza coletiva com atribuições voltadas, dentre outras áreas, para a cultura (art. 15 da LOMAN).

Há também previsão especifica para que a Câmara Municipal de Manaus - CMM legisle sobre "à proteção dos documentos, obras e outros bens de valor histórico, artístico e cultural, como os monumentos, as paisagens naturais notáveis e os sítios arqueológicos do Município", "meios de acesso à cultura, à educação, à ciência, à tecnologia e ao trabalho" e "proteção ao meio ambiente e combate à poluição" (art. 22, alíneas "b", "c" e d", da LOMAN).

Estabelece, também, que deverá haver provisão da destinação de recursos orçamentários para programas que incentivem à cultura (art. 147, §9º da LOMAN). 
Outro ponto que chama atenção, na LOMAN, é a diretriz de Política Urbana traçada que prevê a ordenação do desenvolvimento social dos habitantes da cidade de Manaus, sem prejuízo do respeito às identidades culturais de cada um; também está disposto que a propriedade pública e particular tem que ser exercida observando-se as normas que protegem o Patrimônio Cultural, Histórico e Ambiental (artigos 217 e 220 da LOMAN).

O Art. 332 da LOMAN regula a atuação do município de Manaus frente à cultura e o seu Art. 338 também desse diploma ressalta que "constituem o patrimônio cultural do município os bens tangíveis e de natureza imaterial, portadores de referência à identidade, à ação e à memória dos diferentes grupos formadores da sociedade". Já o Art. 345 que elenca prédios públicos serão inseridos nesse contexto.

Em relação à possibilidade de criação de mecanismos para preservação dos grafites que sejam elaborados na zona territorial do município de Manaus, há disposição no Art. 340 da LOMAN no sentido da proteção, conjuntamente com a comunidade, do patrimônio cultural "por meio de registro, vigilância, tombamento, desapropriação e outras formas de acautelamento e preservação e, ainda, reprimirá ações danosas ou atentatórias à sua integralidade ou caracterização".

O legislador municipal além dos mecanismos de atuação conjunta com a comunidade para proteção do patrimônio cultural, previu no art. 404, I, da LOMAN, a possibilidade da utilização de incentivos extrafiscais voltados à "valorização e difusão das manifestações culturais".

Destaque-se, igualmente, que há estipulação da não incidência do IPTU e do ISS sobre as entidades de cultura (Art. 135, I e IV e Art. 406 da LOMAN).

Dessa forma, ao menos no que tange à proteção das manifestações artísticas legítimas, a legislação internacional, nacional, regional (atinente ao Estado do Amazonas) e local (Município de Manaus) percebe-se que estão bem alinhadas e contém a base de todos os instrumentos necessários para que o grafite não só seja protegido e resguardado para as presentes e futuras gerações, mas estimulado pelo Poder Público, comunidade e setor privado.

E o mais importante é que trata-se da margem fornecida para o intercâmbio cultural voltado ao incentivo da cultura que basicamente foi considerado irrestrito.

Ou seja, derrubou-se fronteiras para que haja uma troca de experiências entre indivíduos situados em locais e realidades distintas para o crescimento mútuo dos artistas e promoção da solidariedade e fraternidade entre os povos dando concreção ao princípio internacional "da cooperação entre os povos para o progresso da humanidade" (Art. 4º IX da CF/88). 
A grande questão que desafia os gestores dos poderes executivos regional e local é a efetivação, a concreção, dos dispositivos normativos já existentes que visam garantir a proteção do patrimônio cultural, a exemplo do grafite que compõe o acervo patrimonial do estado e do município, na qualidade de bem imaterial, o estimulo à produção artística, a valorização da cultura individual de cada grupo e dos artistas.

No entanto, tanto o Poder Público Estadual quanto o Municipal e os particulares, nos últimos 05 (cinco) anos tem dado mais atenção à prática do grafite no âmbito da cidade de Manaus.

Houve, inclusive, a contratação de grafiteiros no ano de 2016 para revitalizar algumas áreas públicas como os que foram realizados no Complexo Viário Gilberto Mestrinho.

Interessante observar que o movimento do grafite que era eminentemente uma "arte de rua" na cidade de Manaus tem se feito presente nos espaços públicos, mas em muitos espaços particulares que vão à restaurantes, academias, lojas, oficinas e etc.

No Amazonas, a Deputada Alessandra Campêlo elaborou o Projeto de Lei nº 192/2017 que ainda está pendente de aprovação, mas que visa regulamentar no âmbito do Amazonas a prática do grafite, dado o seu grande valor agregado à cultura popular e arte urbana, sendo que já no art. $1^{\circ}$, parágrafo único, há previsão de que o conteúdo artístico será reconhecido quando expressar "clara intenção de enriquecer visualmente a paisagem urbana" e "sentimento de valorização das tradições populares, regionais e do rico patrimônio natural, histórico e cultural do Amazonas".

Dentre outros pontos o PL n ${ }^{\circ}$ 192/2017 estipulou que o grafite a ser realizado em bens públicos deve ser previamente autorizado pelo Poder Executivo e que as obras expostas deverão conter a indicação do nome do autor e terão o prazo de validade de 02 (dois) anos, salvo o estabelecimento de prazo distinto pelo Poder Executivo.

Estipular um prazo mínimo de permanência é bem adequado, posto que evita que a troca de gestão do executivo importe numa drástica e antecipada alteração do cenário urbano.

A perpetuação física dos grafites, no entendimento adotado nessa pesquisa, não é adequada porque é bem interessante que as pinturas e gravuras observadas no cenário urbano sejam alteradas conforme a alteração das condições socioeconômicas vividas pelos cidadãos, o que serve também como alerta para a real efetividade das Políticas Públicas que tem sido adotadas como sinalizador das mazelas que ainda precisam ser corrigidas.

Quanto aos bens públicos e locais que poderão abarcar os grafites, o PL no 192/2017, no $\S 2^{\circ}$ do Art. $2^{\circ}$, estipula que caberá ao Poder Executivo, através dos seus órgãos competentes, estabelecer os critérios de identificação dos espaços, equipamentos, imóveis e 
logradouros públicos afeitos ao propósito da presente lei, por meio de regulamentação específica. Para os particulares, contudo, bastará que autorizem o grafiteiro a realizar os trabalhos (Art. $3^{\circ}$ do PL no 192/2017).

Embora entenda-se favorável a tentativa de regulamentação do tema pela parlamentar Alessandra Campêlo, a questão já poderia ser regulamentada na própria lei para evitar que o texto, caso eventualmente seja aprovado, dependa da edição de uma nova norma e permaneça adormecido por mais longos anos, sem contar que alguns pontos, como a ausência de indicação de quais são os órgãos competentes para dar concreção ao mandamento legal, torna mais difícil a interpretação do diploma pelos cidadãos e poderiam facilmente ser alterados.

No âmbito do Município de Manaus, não há norma que aborde diretamente o grafite, os legisladores da cidade de Manaus editaram a Lei do Município de Manaus nº 197/2008, que "autoriza o poder executivo municipal a instituir o programa antipichação no âmbito do município de Manaus e dá outras providências".

A Lei n 197/2008 teve o objetivo de promover o combate à pichação que é tipificada como crime no art. 65 da Lei n. 9.605/98, nos termos do item 3 desta pesquisa, e a restauração das "fachadas" dos bens públicos e particulares que foram pichados, visando, de igual modo, mitigar a poluição ambiental visual, através da realização de limpeza ou pintura reparadora dos muros e fachadas de imóveis públicos e particulares "sempre que forem atingidos por pichação, descaracterizando sua pintura original e comprometendo o combate à poluição visual na cidade de Manaus" (Art. 2º da Lei do Município de Manaus n 197/08).

Já no $\S 1^{\circ}$ do Art. $2^{\circ}$ da Lei $n^{\circ} 197 / 08$, o legislador municipal previu a cooperação entre os entes da federação sempre que bens próprios deles estiverem danificados pela pichação e no $\S 2^{\circ}$ excluiu do âmbito de aplicação do programa instituído pela norma "os grafites efetuados em imóveis particulares ou municipais autorizados pelo proprietário ou autoridade municipal competente" encarando devidamente a distinção entre a prática vândala e a expressão artística.

Fora isso, a Lei n ${ }^{\circ}$ 197/08, pensando na mitigação dos custos do Poder Público, estipulou que a municipalidade poderá valer-se de cooperação com a iniciativa privada para obtenção dos materiais necessários para realização dos reparos, premiando-as com uma plaqueta indicativa de quem apoiou a recuperação.

Trata-se certamente de um avanço, haja vista que a pichação ocasiona drástica poluição ambiental na modalidade visual, pois os rabiscos e traços ininteligíveis feitos com uma técnica ainda muito rudimentar não contém nenhuma mensagem inteligível ou construtiva; figurativamente por si só, os pichadores deixam claro o mero intuito depredador. 
Ademais, favorece o combate a um crime que gera prejuízos ao Poder Público e aos Particulares que continuamente tendem a despender recursos com a restauração de muros e fachadas que perderam as características originais devido às pichações efetuadas.

\section{CONCLUSÃO}

A problemática que motivou essa pesquisa foi a de identificar em qual contexto (crime, arte, cultura, ...) a pichação e o grafite são tipificados, no âmbito jurídico planetário e especificamente em Manaus e no Amazonas.

Os objetivos da pesquisa foram alcançados à medida em que se analisou a legislação internacional, regional e local, permitindo-se chegar a um resultado.

Pode-se concluir que já existe extensa produção normativa em âmbito internacional que foi abarcada pelo ordenamento jurídico brasileiro, assim como normas constitucionais que relegam enorme proteção ao resguardo do patrimônio cultural.

O grafite e a pichação hodiernamente são corretamente diferenciados e, considerando que a primeira atividade está inserida, no patrimônio cultural de cada povo, é licita.

A descriminalização do grafite autorizado separando-o da pichação e daquele realizado à margem das permissões do Poder Público e dos titulares dos bens privados também merece destaque, pois já era tempo da mudança ser realizada pelo legislador federal.

No âmbito do Estado do Amazonas e do Município de Manaus entende-se que a constituição estadual e a lei orgânica Municipal de Manaus já têm conteúdo relevante e que resguarda adequadamente o patrimônio cultural e consequentemente o grafite é licito e manifestação cultural.

Há, entretanto, necessidade da elaboração de leis que regulamentem como os incentivos serão perfectibilizados, como a fiscalização será realizada no meio urbano, expondo aos cidadãos os órgãos competentes, caso existentes, ou criando novos se o custo não afetar drasticamente o orçamento e os cálculos indicarem benefícios socioeconômicos para os jovens que forem incentivados a praticar o grafite, e a maneira pela qual as autorizações para grafitar bens públicos podem ser obtidas.

Em relação à perpetuação das obras de grafite que exponham o panorama social dos artistas, interessante é adotar a virtualização para evitar a perda e que futuramente os habitantes possam acessá-los para comparar as obras realizadas no passado com aquelas feitas na contemporaneidade em que estarão inseridos, adotar restauração na cidade de Manaus exigiria continuamente recursos haja vista o alto índice pluviométrico da região, sendo mais importante garantir que o panorama urbano cotidianamente seja modificado e encampe os 
sentimentos presentes dos artistas servindo de sinalizador para a real efetividade e alcance das políticas sociais.

\section{REFERÊNCIAS}

AMAZONAS. Constituição do Estado do Amazonas: promulgada em 05 de outubro de 1989. Diário Oficial do Estado, Amazonas, Brasil, em 05 de out. de 1989. Disponível em http://www.pge.am.gov.br/wp-content/uploads/2017/11/CEAM-Atualizada-ate-EC-96-de2017.pdf . Acesso em: 02 jun. 2019.

AMAZONAS. Projeto de Lei $\mathbf{n}^{\mathbf{0}}$ 192/2017, de autoria da Deputada Alessandra Campêlo. Assembleia Legislativa do Estado do Amazonas.

BIAGI, Orivaldo Leme. A Contracultura e o Rok'nRoll: A Relação dos Movimentos de Contestação Social e a Música Jovem dos Anos 60 e 70. Revista MOMENTUM, v. 1, n. 7 , p. 163-184, 2017.

BRASIL. Constituição (1988). Constituição da República Federativa do Brasil: promulgada em 05 de outubro de 1988. Congresso Nacional, Brasília, 1.988.

BRASIL. Lei Federal n. 12.408, de 25 de maio de 2011. Altera o art. 65 da Lei no 9.605, de 12 de fevereiro de 1998, para descriminalizar o ato de grafitar, e dispõe sobre a proibição de comercialização de tintas em embalagens do tipo aerossol a menores de 18 (dezoito) anos. Congresso Nacional, Brasília, 2011.

BRASIL. Lei Federal n. 9.605, de 12 de fevereiro de 1998. Dispõe sobre as sanções penais e administrativas derivadas de condutas e atividades lesivas ao meio ambiente, e dá outras providências. Congresso Nacional, Brasília.

BRASIL. Lei $\mathbf{n}^{\mathbf{0}}$ 6.938/81 - Lei de Política Nacional do Meio Ambiente. Congresso Nacional: Brasília, 1.981.

BRITO, Fausto; HORTA, Cláudia Júlia Guimarães; AMARAL, Ernesto FL. A urbanização recente no Brasil e as aglomerações metropolitanas. Disponivel em Open Science Framework Preprints, August 18. https://doi.org/10.31219/osf.io/84b92; 2018.

BULOS, Uadi Lammêgo. Curso de Direito Constitucional - São Paulo: Saraiva, 2011.

CARDOZO, Henrique Ribeiro; COSTA, Daniela Carvalho Almeida da; RAMOS, Lucilla Menezes da Silva. Patrimônio Cultural E A Preservação Do Passado Pelo Estado: Um Estudo Sobre O Processo De Desapropriação Do Quadro "Miséria E Caridade" Do Pintor Sergipano Horácio Hora. Revista Jurídica, [S.1.], v. 2, n. 55, p. 272 - 295, abr. 2019. ISSN 2316-753X. Disponível em: <http://revista.unicuritiba.edu.br/index.php/RevJur/article/view/3393/371371829>. Acesso em: 23 abr. 2020. doi:http://dx.doi.org/10.21902/revistajur.2316-753X.v2i55.3393. 
DECLARAÇÃO UNIVERSAL DOS DIREITOS HUMANOS. Assembleia Geral das Nações Unidas em Paris. 10 dez. 1948. Disponível em: https://nacoesunidas.org/wpcontent/uploads/2018/10/DUDH.pdf. Acesso em: 07 jun. 2019.

ENDO, Tatiana Sechler. A pintura rupestre da pré-historia e o grafite dos novos tempos. São Paulo, 2009. Disponivel em scholar.google.com.br/scholar. Consultada em 03 ago. 2019

GONTIJO, Mariana Fernandes. As Culturas do Graffite e do Hip Hop como constituintes do Patrimônio Cultural brasileiro. Dissertação de mestrado UFMG. Belo Horizonte, 2012. Disponível em http://www.bibliotecadigital.ufmg.br/dspace, consultada em 10 ago. 2019.o

JABORANDY, Clara Cardoso Machado; MARTINI, Sandra Regina; RESTO, Elígio. Direito e Fraternidade: a Dignidade Humana como Fundamento. Revista do Direito, v.3, n.53, p.92/103, 2017.

LAZZARIN, Luís Fernando. Grafite e o Ensino da Arte. Educação \& Realidade, v. 32, n. 1, p. 59-73, 2007.

MANAUS. Lei $\mathrm{n}^{\circ}$ 197, de 19 de novembro de 2008. Autoriza o poder executivo municipal a instituir o programa antipichação no âmbito do município de Manaus e dá outras providências. Diário Oficial do Município, Manaus, AM, 24 de nov. de 2008. Disponível em https://leismunicipais.com.br/a/am/m/manaus/lei-promulgada/2008/19/197/lei-promulgada-n197-2008-autoriza-o-poder-executivo-municipal-a-instituir-o-programa-antipichacao-noambito-do-municipio-de-manaus-e-da-outras-providencias. Acesso em: 02 de jun. de 2019.

MANAUS. Lei Orgânica do Município de Manaus: promulgada em 05 de abril de 1990. Diário Oficial do Município, Manaus, AM, 27 de dez. de 1985. Disponível em https://www.legisweb.com.br/legislacao/?id=179611. Acesso em: 02 de jun. de 2019.

ORGANIZAÇÃO DAS NAÇÕES UNIDAS PARA A EDUCAÇÃO, A CIÊNCIA E A CULTURA. Convenção sobre a Proteção do Patrimônio Mundial, Cultural e Natural, 23 novembro 1973. Disponível em: https://whc.unesco.org/archive/com vention-pt.pdf; Acesso em: 26 abr. 2019.

ORGANIZAÇÃO DAS NAÇÕES UNIDAS PARA A EDUCAÇÃO, A CIÊNCIA E A CULTURA. Convenção para Salvaguarda do Patrimônio Cultural Imaterial, 17 outubro 2003. Disponível em: https://ich.unesco.org/doc/src/00009-PT-Portugal-PDF.pdf ; Acesso em: 26 abr. 2019.

PENNACHIN, Deborah Lopes. Signos Subversivos: das significações de Graffiti e Pichação. In: XXVI Congresso Anual em Ciência da Comunicação, Belo Horizonte/MG. 2003.

POZZETTI, Valmir César e PRESTES, Fernando Figueiredo. A primeira norma técnica para cidades sustentáveis: uma reflexão sobre a problemática urbana. Rev. de Direito Urbanístico, Cidade E Alteridade | e-ISSN: 2525-989X| Porto Alegre | v. 4 | n. 2 | p. 117 - 134 | Jul/Dez 2018.

POZZETTI, Valmir césar. Aula ministrada em 20 maio 2019, disciplina Direito urbanístico, no Programa de mestrado em Direito Ambiental da Universidade do Estado do Amazonas. 
RAMOS, Celia Maria Antonacci. Grafite \& pichação: por uma nova epistemologia da cidade e da arte. Encontro Da Associação Nacional De Pesquisadores Em Artes Plásticas, v. 16, 2007.

RAMOS, Cristovam. Urbanismo: pequena abordagem do crime de pichação. MPMG Jurídico, 2012.

SILVA, José Afonso da. Direito Ambiental Constitucional, São Paulo, Malheiros: 1998.

SILVA, Solange Teles da. Poluição visual e poluição sonora: aspectos jurídicos. id/496891, 2003.

SIRVINKAS, Luiz Paulo. Manual de Direito Ambiental. São Paulo: Saraiva, 2012.

ZUIN, Aparecida. O grafite da vila madalena: uma abordagem sociossemiótica. Revista Internacional de Folkcomunicação, v. 2, n. 3, 2008. 